\title{
Telematik: KVen bremsen Ärzte, kassieren aber schon
}

_ Das klingt nach zügiger Durchführung: Die KBV hat dem GKV-Spitzenverband bereits eine erste Rechnung für die Einführung der Telematik-Infra-

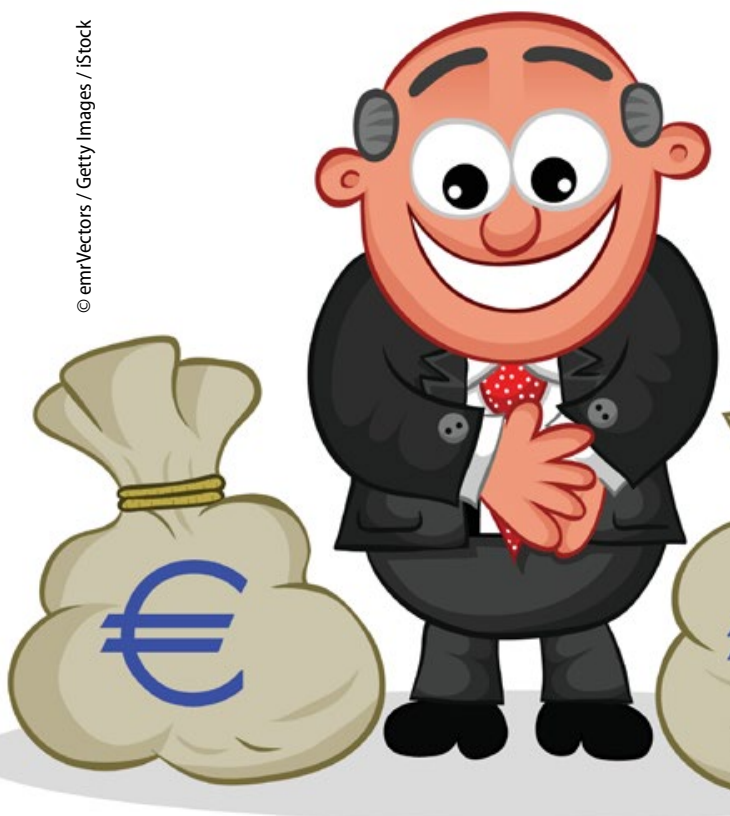

Bei den KVen sammelt sich Geld an. struktur (TI) in den Vertragsarztpraxen präsentiert. Konkret geht es um die Abschlagszahlungen für das 3 . und 4 . Quartal 2017. Die KBV hat dafür auf Basis der von den einzelnen KVen gemeldeten Daten den jeweiligen Finanzierungsbedarf ermittelt. Entsprechend einer Vereinbarung mit den Kassen werden so bis zum Jahresende bereits $30 \%$ des voraussichtlichen Gesamtfinanzierungsbedarfs zuzüglich der Betriebskosten auf den KV-Konten eingehen.

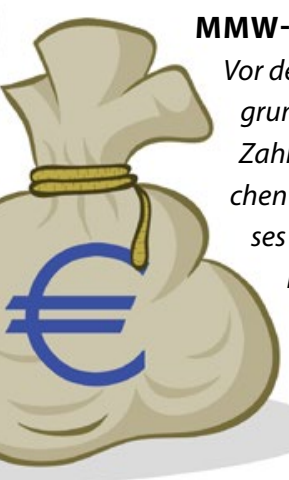

MMENTAR

or dem Hintergrund der grundsätzlich schlechten Zahlungsmoral der gesetzlichen Krankenkassen ist dieses Tempo verwunderlich.

Die Kassen sollen bis zum 30. September 2017 das Geld für das 3. und 4. Quartal an die KBV überweisen. Spätestens zehn Werktage

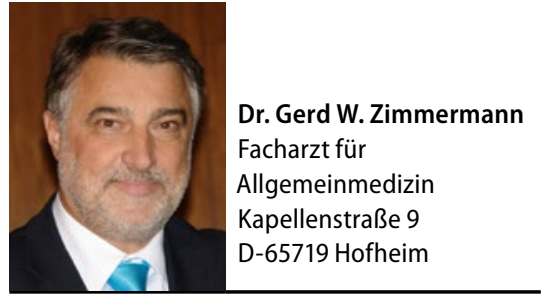

nach dem Zahlungseingang sollen die Regional-KVen dann bereits über das Geld verfügen. Bis zum 15. November 2017 wird die KBV darüber hinaus die Höhe und die Zahlungstermine der restlichen Abschläge im Jahr 2018 festlegen.

Seltsam ist dieses rasante Vorgehen v. a. vor dem Hintergrund, dass aus KBV- und KV-Kreisen immer wieder verlautet, dass der Terminplan des TI-Roll-outs gar nicht eingehalten werden kann. In der Tat warnen momentan viele KVen davor, Angebote von Praxissoftwareanbietern zur Umsetzung der TI voreilig anzunehmen. Der Haken an der Sache ist natürlich, dass man nur im 3. Quartal 2017 die höchste Pauschale für die Anschaffung und Installation der neuen Geräte erhält. Wer sich an die Warnungen seiner KV hält und länger wartet, bekommt weniger Geld (siehe MMW 13/2017, S. 24).

Die Frage drängt sich also auf: Wie passt das zusammen? Was machen die KVen mit dem Geld, das sie bei den Kassen abrufen, wenn sie gleichzeitig dafür sorgen, dass im 3. und 4. Quartal kaum Praxen an die Tl angeschlossen sind?

\section{Laborüberweisungen jetzt digital möglich}

_ Seit dem 1. Juli 2017 können Laborüberweisungen und Anforderungsscheine für Laboruntersuchungen bei Laborgemeinschaften mit den digitalen Vordrucken 10 und 10A auch elektronisch erstellt und ausgetauscht werden. Die Anwendung ist bisher freiwillig - die Nutzung konventioneller Vordrucke bleibt also möglich. Um an dem elektronischen Austausch teilnehmen zu können, benötigt man eine entsprechend zertifizierte Praxissoftware, eine sichere
Verbindung für Datenübermittlung (z.B. KV-Connect) sowie für den Vordruck 10 einen elektronischen Heilberufsausweis (eHBA) mit Kartenterminal und Signatursoftware.

Die KBV hat eine Zulassungsliste zur „Labordatenkommunikation“ veröffentlicht, die alle zertifizierten Softwaresysteme für die digitalen Formulare 10 und 10A auflistet (www.kbv.de/html/5614. php). Der eHBA kann über die Landesärztekammer beantragt werden.

\section{MMW-KOMMENTAR}

Spätestens mit der (Zwangs-)Einführung des Versichertenstammdatenmanagements (VSDM) im Jahr 2018 muss der Vertragsarzt sowieso einen eHBA haben. KBV und Kassen haben in diesem Zuge vereinbart, dass die Praxen die Kosten für diese neue Ausweismöglichkeit von 11,63 Euro pro Quartal ersetzt bekommen. So gesehen lohnt es sich also, mit der Umsetzung der digitalen Laborüberweisung bis zur endgültigen Einführung der Telematik-Infrastruktur zu warten. 